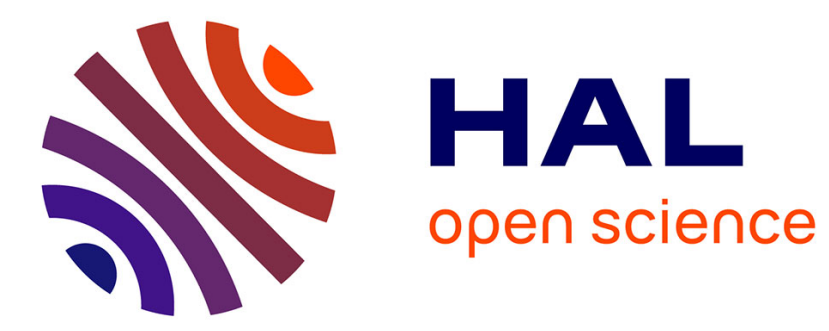

\title{
Risk factors for motorcycle loss-of-control crashes
}

Dan Wu, Martine Hours, Jean-Louis Martin

\section{To cite this version:}

Dan Wu, Martine Hours, Jean-Louis Martin. Risk factors for motorcycle loss-of-control crashes. Traffic Injury Prevention, 2017, 15 p. 10.1080/15389588.2017.1410145 . hal-01664444

\section{HAL Id: hal-01664444 \\ https://hal.science/hal-01664444}

Submitted on 14 Dec 2017

HAL is a multi-disciplinary open access archive for the deposit and dissemination of scientific research documents, whether they are published or not. The documents may come from teaching and research institutions in France or abroad, or from public or private research centers.
L'archive ouverte pluridisciplinaire HAL, est destinée au dépôt et à la diffusion de documents scientifiques de niveau recherche, publiés ou non, émanant des établissements d'enseignement et de recherche français ou étrangers, des laboratoires publics ou privés. 


\title{
Risk factors for motorcycle loss-of-control crashes
}

\author{
Authors \\ Dan $\mathrm{Wu}^{\mathrm{a}}$ \\ Martine Hours ${ }^{\text {a }}$ \\ Jean-Louis Martin ${ }^{a}$
}

a: Univ Lyon, Université Lyon 1, IFSTTAR, UMRESTTE UMR_T 9405, F-69675, LYON, France

\section{Corresponding author:}

Dan WU

IFSTTAR/UMRESTTE, 25 Avenue François Mitterrand, 69675 Bron Cedex, France

Tel.: +33478656863;

E-mail: dan.wu@ifsttar.fr 


\begin{abstract}
Objective: The present paper identifies and assesses the effect of critical factors on the risk of motorcycle lossof-control (LOC) crashes.

Method: Data come from a French project on road crashes, which comprises all fatal road crashes and a random sample of $1 / 20^{\text {th }}$ of non-fatal crashes in France in 2011, based on police reports. A case-control study was carried out on a sample of 903 crashes for 444 LOC motorcycle riders (case) and 470 non-LOC and non-responsible motorcycle riders (control). The sample was weighted due to the randomization of non-fatal crashes. Missing values were imputed using multiple imputation.

Results: Road alignment and surface conditions, human factors and motorcycle type played important roles in motorcycle LOC crashes. Riding in a curve was associated with a 3-fold greater risk of losing control of motorcycle than riding in a straight line. Poor road adhesion significantly increased the risk of losing control; the risk increased more than 20-fold when deteriorated road adhesion was encountered unexpectedly, due to loose gravel, ice, oil, bumps, road-marking, metal plates, etc. For motorcyclists, riding with a positive blood alcohol concentration (over or equal to the legal limit of $0.5 \mathrm{~g} / \mathrm{l}$ ) was very dangerous, often resulting in losing control. The risk of LOC crash varied for different types of motorcycle: riders of roadsters and sports bikes were more likely to have a LOC crash than riders of basic or touring motorcycles. In addition, LOC risk increased with speed; a model using the square of the traveling speed showed better fit than one using speed itself.
\end{abstract}

Conclusion: The LOC crash factors related to riders, vehicles and road infrastructure identified here were expected, but were rarely identified and taken simultaneously into account in previous studies. They could be targeted by countermeasures to improve motorcyclist safety.

Key-words: motorcycle, LOC, curve, road adhesion, motorcycle type, traveling speed 


\section{INTRODUCTION}

In France, the number of motorcycle fatalities is steadily decreasing, from 947 in 2000 to 625 in 2014. This significant decline of $34 \%$ for motorcycle riders, however, is less than for car users, which was $69 \%$ over the same period. Although motorcycles account for only $1.5 \%$ of overall road traffic, they are particularly at risk of crash injury, associated with $24 \%$ of crashes in 2014 (ONISR 2016). According to recent research in France, the risk of death or injury per kilometer was 20-30 times greater for powered two-wheeler riders than for car drivers (Blaizot et al. 2013; Bouaoun et al. 2015; SOeS 2013a).

Over $50 \%$ of serious motorcycle crashes in the UK resulted from right-of-way violations or losing control on curves (38\% and 15\%, respectively) (Clarke et al. 2007). In a recent study in Germany, loss-of-control (LOC) crashes were the most common scenario $(26 \%)$ in powered two-wheeler crashes with severe injury (Fredriksson and Sui 2016). In Belgium, the MOTAC (Motorcycle Accident Causation) study showed that motorcyclists had lost control in $32 \%$ of the cases studied (Martensen and Roynard 2013). Similar results were previously reported by Preusser in 1995, with LOC crashes accounting for $48 \%$ of fatal motorcycle crashes: $41 \%$ "ran-off-road" and 7\% “motorcycle down" (Preusser et al. 1995).

In short, although LOC crashes are not the most frequent type of motorcycle crash overall, when they happen they tend to be serious and are one of the most common motorcycle crash types leading to fatal or serious injury. Prevention of LOC crashes is imperative, to reduce the risk of motorcyclists being killed or seriously injured. That is one reason why the present paper focuses on this point. Also, few studies of motorcycle crashes focused on this specific crash type.

Some articles reported that motorcycle crashes were often due to risky rider behavior: riding under the influence of alcohol, fast driving, unlicensed driving, etc. Preusser reported that alcohol and excessive speed were common factors associated with motorcycle crashes (Preusser et al. 1995). Alcohol can impair the skills involved in motorcycle control (Creaser et al. 2009). Ouellet showed that motorcyclists riding under the influence of alcohol were more likely to be involved in a LOC crash, especially at night (Ouellet and Kasantikul 2006). According to Horswill, motorcyclists drive faster than motorists (Horswill and Helman 2003). Excessive or inappropriate speed is a very common rider-related factor in motorcycle crashes (Elliott et al. 2007; Hurt et al. 1981; Lardelli-Claret et al. 2005; Van Elslande and Elvik 2012). At excessive speed, motorcycles are more difficult to maneuver especially on curves and riders do not have time to handle urgent situations well (obstacles or slippery objects such as ice or oil on the road surface), resulting in loss of control. A strong effect of motorcycle type was found for risky driving behavior in fatal crashes, due to motorcycle design and performance; sports bikes in particular were associated with elevated risk taking (Teoh and Campbell 2010).

The literature stresses the risk associated with curves, with a high frequency of LOC crashes on curves (Clarke et al. 2007; Hurt et al. 1981; Sexton et al. 2004; Van Elslande et al. 2008). Schneider's study suggested that a curve with a decreasing radius caused a significant increase in crash frequency and that the longer the curve the greater the crash risk (Schneider et al. 2010).

Road surface deterioration, damaged bitumen or the presence of some small objects on the roadway (gravel, ice, oil, etc.) was reported in $30 \%$ of powered two-wheeler crashes in the in-depth MAIDS (Motorcycle Accidents In Depth Study), but their actual implication in the accidents was not detailed (ACEM 2009). Poor road conditions were closely related to motorcycle LOC and were considered causal in $6.5 \%$ of single-vehicle 
crashes (Hurt et al. 1981). Likewise in France degraded road condition was identified as causal in $7 \%$ of motorcycle and $18.5 \%$ of moped LOC crashes (Van Elslande et al. 2008).

The present case-control study aimed to identify critical risk factors for motorcycle LOC crashes, and assess their effects. These factors, related to riders, vehicles and road infrastructure, will then be targeted for countermeasures to reduce the rate of motorcycle LOC crashes.

\section{MATERIAL AND METHODS}

Our analyses relied on data from the VOIESUR project (Véhicule Occupant Infrastructure Etudes de la Sécurité des Usagers de la Route) (VOIESUR 2012), which were coded in detail for all fatal road crashes and for a random sample of $1 / 20^{\text {th }}$ of non-fatal crashes in France in 2011, based on the police reports. For each crash, at least 350 variables were coded in the database, including general crash characteristics based on the police reports and some other important information extracted by accidentology experts using the elements available concerning the crash: for instance, loss of control, responsibility, human functional failure, collision, traveling speed, impact speed, etc.

The database comprised 1,420 motorcycle crashes: 725 fatal, 695 non-fatal; these included 441 motorcycle LOC crashes in which at least one rider lost control of a motorcycle: 327 fatal and 114 non-fatal. Thus, motorcycle LOC concerned about $45 \%$ of fatal and 16\% of non-fatal motorcycle crashes in France in 2011.

Before considering the study sample and analysis method, two concepts need to be defined: "motorcycle LOC crash" and "expert responsibility".

\section{Motorcycle LOC Crashes}

Motorcycle LOC crashes are defined by loss of control of the motorcycle alone causing the crash, without involvement of other road users (vehicles, pedestrians) contributing to the loss of control. This definition comes from a French report (Michel et al. 2005) and was used in some previous studies (Van Elslande et al. 2008).

\section{Expert Responsibility}

Within the project VOIESUR, the responsibility of users involved in a crash, so-called "expert responsibility", was determined by accidentology experts using all elements available concerning the crash. "Expert responsibility" is not intended in a legal sense, but in the sense that a responsible agent contributed to or triggered the crash by maneuvering inappropriately. It is scaled at 5 decreasing levels: totally responsible, rather responsible, shared responsibility, rather non-responsible, and not responsible at all. In the present study, the first three levels were counted as "responsible" and the other two as "non-responsible".

\section{Method: Case-Control Study of Motorcycle LOC Crashes}

To assess motorcycle LOC crash factors, a case-control study was conducted, comparing LOC motorcycle riders with a control group supposed to be representative of the general population of motorcycle riders on the road. Initially, we considered comparing LOC riders with a control group of crash-involved riders who did not lose control of the motorcycle (non-LOC riders). We then decided to exclude "responsible" riders from the control group, to have a sample that was more representative of the population of riders, according to the "quasiinduced exposure method" developed by epidemiological researchers, on the assumption that non-responsible 
drivers are involved in crashes fortuitously and can constitute a representative sample of the population of drivers (Lardelli-Claret et al. 2005; Lenguerrand et al. 2008; Moskal et al. 2012; Stamatiadis and Deacon 1997).

Thus, the study sample comprised 903 motorcycle crashes (485 fatal, 418 non-fatal), involving 914 motorcyclists: 444 LOC riders (cases) and 470 non-LOC non-responsible riders (controls). The selection process is shown in Figure 1.

Figure 1: Sample selection flow-chart

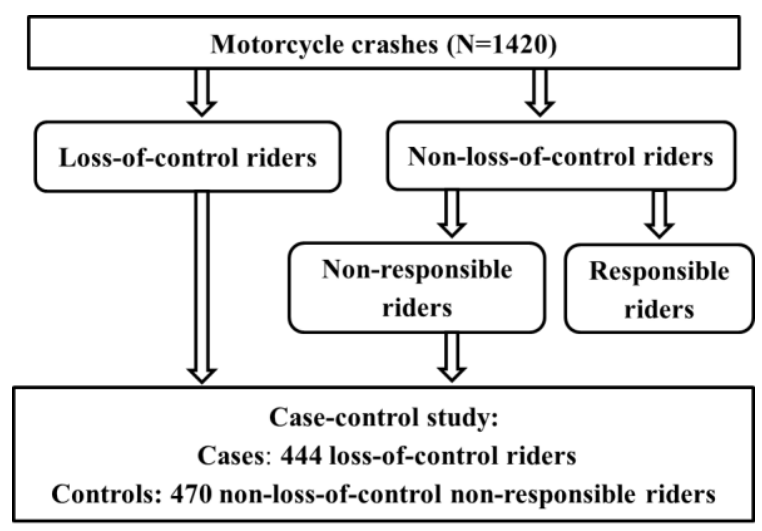

\section{Potential Risk Factors}

Potential risk factors were grouped as:

- rider-related (gender, age, blood alcohol concentration, driving license and experience, trip purpose, traveling speed);

- vehicle-related (engine displacement, motorcycle type);

- environment-related (weekend vs. weekday, light conditions, weather conditions);

- or infrastructure-related (urban/non-urban area, type of road, posted speed limit, roadway alignment, road adhesion).

In the absence of any official or consensual definition, different types of motorcycle were defined as in a 2012 survey of powered two-wheeled vehicles in France (SOeS 2013b), in 8 categories in the database: basic, roadster, cruiser, scooter, tourer/grand tourer, sports bike, dual-purpose, and off-road (definition of these eight categories is given in appendix Text A1); basic and touring motorcycles were combined in a single category for the study. For road adhesion, two types of deterioration were distinguished: 1) "predictable poor adhesion": wet, snowy or deformed roads, which are predictable for riders, who can then adapt their driving; and 2) "unpredictable poor adhesion": mud, gravel, ice, oil, bumps, road markings or metal plates, etc., which are difficult to foresee or detect, and thus difficult to manage.

\section{Missing Data}

The study sample contained missing data on certain potential risk factors. Blood information was missing in $15.2 \%$ of records, motorcycle type in $5.0 \%$, road adhesion in $3.8 \%$ and traveling speed in $56.6 \%$. It is often difficult to collect enough information about crashes to evaluate the traveling speed of a vehicle, particularly when the outcome was not serious, therefore traveling speed was less often estimated in non-fatal (34\%) against than fatal crashes (51\%).

Missing values were imputed using multiple imputation with a Fully Conditionally Specification (FCS) method (Van Buuren 2007), separately for fatal and non-fatal crashes. The imputation models included the 
outcome variable (loss of control) and all variables of interest (blood alcohol concentration, motorcycle type, road alignment, road adhesion, weekend vs. weekday, and traveling speed). Some auxiliary variables associated with the missing mechanism or correlated with traveling speed were also included in the imputation model for traveling speed: severity of injury, posted speed limit, weather conditions, lighting conditions, and compliance with traffic rules. In addition, time of day (day/night) was added to the imputation model for blood alcohol concentration.

Fifty imputed data sets were created using SAS software version 9.4 (procedure proc mi). In subsequent analyses, estimates were calculated for each imputed data set, and then combined to assess final estimates and variance matrix (proc mianalyze).

\section{Data Weighting}

As described above, the VOIESUR database includes all fatal crashes and $1 / 20^{\text {th }}$ of non-fatal crashes, therefore a weighting of 1 for fatal crashes and 20 for non-fatal crashes was applied in the present study. All analyses took account of this weighting, using SAS software (procedures surveymeans, surveyfreq, surveylogistic).

\section{Statistical Analysis}

Analyses were carried out in two steps. Firstly, cases were compared to controls with observed data (taking account of the weighting), using the Wald test (t-test for speed), to select risk factors for motorcycle LOC crashes. Variables with p-value $<0.2$ were selected. Secondly, crude and adjusted odds ratios (OR) were estimated according to selected variables, using univariate logistic regression and multivariate logistic regression on the weighted, imputed data.

\section{RESULTS}

Analysis covered 914 motorcyclists: 444 LOC (cases) and 470 non-LOC non-responsible riders (controls). Taking weighting into consideration, 2,629 cases and 6,284 controls were covered.

\section{Step 1: Factors Associated with Motorcycle LOC Crashes}

Table A1 shows the distribution of cases and controls according to potential risk factors for motorcycle LOC crashes. 5\% of LOC riders were between 16 and 17 years old. 86\% were tested for blood alcohol; about 16\% of tests were positive (over or equal to the legal limit of $0.5 \mathrm{~g} / \mathrm{l}$ ). Apart from $34 \%$ missing data for trip purpose, $40 \%$ of LOC riders lost control of their motorcycle on a leisure trip. More than $40 \%$ lost control at weekends, about $15 \%$ at night without light or with light off, and $12 \%$ in bad weather conditions. Over half lost control on a curve. More than $30 \%$ lost control on a road with poor adhesion; in particular, $14 \%$ concerned slippery objects on the road.

According to Wald tests, blood alcohol concentration, motorcycle type, weekend vs. weekday, lighting conditions, weather conditions, urban/non-urban area, road type, road alignment, road adhesion, posted speed limit and traveling speed could potentially influence LOC crashes. These factors were selected for subsequent analyses, except for some which were strongly associated with our variables of interest: weather conditions associated with road adhesion, and urban/non-urban area, road type and posted speed limit associated with 
traveling speed. Corresponding associations are shown in Table 1 as well as associations among other risk factors, which will be examined in the discussion section.

Table 1: Association between certain risk factors in the control group

\begin{tabular}{l|l|r|r}
\hline & & Statistic & P-value \\
\hline Blood alcohol & Age* & $\chi^{2}=3.91$ & 0.27 \\
concentration & Day of week & $\chi^{2}=0.15$ & 0.69 \\
\hline \multirow{2}{*}{ Motorcycle type* } & Age* & $\chi^{2}=38.1$ & 0.0015 \\
& Validity of driving license & $\chi^{2}=5.06$ & 0.75 \\
\hline & Age & $\mathrm{F}=5.66$ & $<.0001$ \\
& Blood alcohol concentration & $\mathrm{F}=1.20$ & 0.27 \\
& Motorcycle type & $\mathrm{F}=3.49$ & 0.0027 \\
& Day of week & $\mathrm{F}=5.10$ & 0.025 \\
Traveling speed & Road alignment & $\mathrm{F}=11.5$ & 0.0008 \\
& Road adhesion & $\mathrm{F}=8.81$ & 0.0034 \\
& Area & $\mathrm{F}=76.8$ & $<.0001$ \\
& Type of road & $\mathrm{F}=25.9$ & $<.0001$ \\
& Posted speed limit & $\mathrm{F}=25.0$ & $<.0001$ \\
\hline Road adhesion & Weather & $\chi^{2}=26.9$ & $<.0001$ \\
\hline
\end{tabular}

*Some categories were grouped for doing statistical tests due to small numbers in the control group.

The risk of LOC crashes was higher on rainy day than sunny or cloudy days: OR=2 (Table A1). Bad weather conditions may lead to loss of control due to loss of adhesion on a wet or slippery road, implying a strong association between weather and road adhesion; only road adhesion was therefore taken into account for subsequent analyses.

Concerning variables strongly associated with traveling speed (urban/non-urban area, road type and posted speed limit), LOC risk was greater in non-urban areas, with speed limits above $50 \mathrm{~km} / \mathrm{h}$ and on motorways. However, these variables were not selected for subsequent analyses as, despite some missing data, traveling speed was known and was an essential factor in LOC crashes.

Comparing traveling speed between cases and controls, LOC riders rode significantly faster than controls: respectively, $68.4 \mathrm{~km} / \mathrm{h}$ and $53.3 \mathrm{~km} / \mathrm{h}$. To determine the best model explaining the LOC outcome by the traveling speed, several models were fitted to observations with known speed with a linear, quadratic, quadratic polynomial or cubic polynomial relation. The quadratic polynomial model was best in terms of minimizing information loss (Akaike Information Criterion (AIC) $=3,455$ ), followed by the model using the square of the speed (AIC $=3,465$ ). However, once the square of the traveling speed was included in the model, the linear term of speed had only a very small contribution; so, for simplicity, we chose the model with only the square of the speed.

\section{Step 2: Risk of Losing Control}

Multiple imputation was implemented at this step. Table 2 shows the distribution of cases and controls according to LOC crash risk factors, with corresponding crude and adjusted OR, using imputed data and taking weighting into account. 
Table 2: Distribution of cases and controls according to risk factors for motorcycle loss-of-control crash involvement, crude and adjusted OR and $95 \%$ CI (Column percentages were weighted and averaged from 50 independent imputations)

\begin{tabular}{|c|c|c|c|c|c|}
\hline Risk factors & & $\begin{array}{r}\text { Case } \\
\mathrm{N}=2,629 \\
\end{array}$ & $\begin{array}{r}\text { Control } \\
\mathrm{N}=6,284\end{array}$ & Univariate analysis & Multivariate analysis \\
\hline \multirow{2}{*}{$\begin{array}{l}\text { Blood alcohol } \\
\text { concentration }\end{array}$} & Negative & 84.1 & 99.8 & 1.0 & 1.0 \\
\hline & Positive & 15.9 & 0.2 & $114[41 ; 322]$ & $103.3[30 ; 351]$ \\
\hline \multirow{7}{*}{$\begin{array}{l}\text { Motorcycle } \\
\text { type }\end{array}$} & Scooter & 21.5 & 37.1 & $0.8[0.4 ; 1.4]$ & $1.2[0.5 ; 2.8]$ \\
\hline & Basic/tourer & 17.8 & 23.6 & 1.0 & 1.0 \\
\hline & Cruiser & 4.8 & 3.0 & $2.2[0.7 ; 6.5]$ & $2.5[0.6 ; 10.1]$ \\
\hline & Roadster & 25.9 & 20.6 & $1.7[0.9 ; 3.1]$ & $2.4[1.04 ; 5.4]$ \\
\hline & Sports bike & 14.9 & 6.6 & $3.0[1.4 ; 6.3]$ & $3.9[1.3 ; 11.5]$ \\
\hline & Dual-purpose & 11.5 & 8.4 & $1.8[0.8 ; 4.0]$ & $2.7[0.96 ; 7.4]$ \\
\hline & Off-road & 3.6 & 0.7 & $7.2[1.3 ; 39.6]$ & $7.5[1.3 ; 44.7]$ \\
\hline \multirow{2}{*}{ Day of week } & Weekdays & 56.7 & 81.1 & 1.0 & 1.0 \\
\hline & Weekends & 43.3 & 18.9 & $3.3[2.1 ; 5.0]$ & $2.7[1.5 ; 4.8]$ \\
\hline \multirow{2}{*}{$\begin{array}{l}\text { Road } \\
\text { alignment }\end{array}$} & Straight line & 43.3 & 79.3 & 1.0 & 1.0 \\
\hline & Curve & 56.7 & 20.7 & $5.0[3.3 ; 7.7]$ & $3.5[2.0 ; 6.1]$ \\
\hline \multirow{3}{*}{$\begin{array}{l}\text { Road } \\
\text { adhesion }\end{array}$} & Normal adhesion & 67.9 & 87.4 & 1.0 & 1.0 \\
\hline & Predictable poor adhesion & 18.0 & 11.6 & $2.0[1.1 ; 3.5]$ & $4.6[2.2 ; 9.6]$ \\
\hline & Unpredictable poor adhesion & 14.1 & 1.0 & $18.1[5.2 ; 62.3]$ & $28.4[8.1 ; 100]$ \\
\hline \multicolumn{2}{|l|}{ Square of speed } & & & $1.0002[1.0001 ; 1.0003]$ & $1.0002[1.00002 ; 1.0003]$ \\
\hline
\end{tabular}

Six major factors for LOC crashes were significant. Risk of LOC crash was extremely high in case of positive blood alcohol concentration (OR=103). Motorcycle type also affected LOC risk: roadsters, sports bikes, dual-purpose sports bikes and off-road motorcycles were associated with higher risk than basic or touring motorcycles; off-road motorcycles were the highest-risk type, with $\mathrm{OR}=7.5$. Riding at weekends showed greater LOC risk than riding on weekdays. Concerning road infrastructure, risk of losing control was higher in curves than in straight sections $(\mathrm{OR}=3.5)$. Predictable poor adhesion could disturb normal riding, increasing LOC risk 4.6-fold, but unpredictable poor adhesion was much more dangerous, with $\mathrm{OR}=28$. As expected, LOC crash risk increased significantly with the square of the speed $(\mathrm{p}<0.03)$.

\section{DISCUSSION}

The present case-control study analyzed the association between LOC crashes and potential risk factors related to rider, motorcycle, environment and road infrastructure. Risk of losing control of the motorcycle was strongly associated with riding under the influence of alcohol, the square of the speed, motorcycle type, weekend vs. weekdays, road alignment and road surface conditions.

\section{Road Alignment and Road Surface Conditions}

The most important findings were the effects of road alignment and of road surface conditions on loss of control, which were expected but seldom estimated from real-life crash data. As is well known, motorcyclists have to pay more attention to all road conditions than vehicle drivers, since motorcycles are more sensitive to environmental disturbances, because of physical specificities of motorcycles: small, light, unstable with two wheels. Due to the small contact surface between wheel and road, loss of adhesion is a problem on slippery or deformed roads or with slippery objects on the road, etc. It was therefore important that these factors emerged in our study. Riding in a curve was associated with a 3-fold higher LOC risk than riding in a straight line. Poor road adhesion significantly increased LOC risk, particularly $(\mathrm{OR}=28)$ when deterioration of road adhesion was encountered unexpectedly due to loose gravel, oil, potholes or bumps on the road. LOC risk was 4 times higher on a wet, snowy or deformed road than on a dry road in good condition: although motorcyclists were aware of 
the deterioration of road adhesion and rode with more caution, they still risked skidding out, either underestimating the risk or overestimating their skill.

As shown in Table 1, road adhesion was strongly associated with weather conditions. Since road adhesion was partially determined from weather conditions, the latter was not considered alone as a risk factor for LOC crashes, even though wet weather could reduce the rider's visibility, which potentially could change the rider's judgment about the driving environment and lead to a LOC crash.

\section{Motorcycle Type}

Motorcycles vary in design and performance; riders often select their bike according to riding preferences, price, trip purposes, etc. Eyssartier highlighted the difference between motorcyclists according to the type of motorcycle they ride (Eyssartier et al. 2017). Certain papers studied death/crash rates according to motorcycle type. Supersport motorcycles were associated with higher rider death rates (Teoh and Campbell 2010); in a 2004 exposure survey of motorcyclists, crash rate was found to be highest for trail and dual-use motorcycles, and more than the double of that for sports bikes (Harrison and Christie 2005).

In the present study, roadster riders had a greater risk of losing control than basic or touring motorcycle riders, and riding a sports bike was more risky than riding a roadster. This could not be due to road holding, which is as good or better for these motorcycles than for basic or touring motorcycles, but rather was likely due to rider behavior or characteristics to these types of motorcycle.

Associations between motorcycle type and both age of rider and validity of driving license were tested. No significant association was found between motorcycle type and validity of driving license, but one was found between motorcycle type and age of rider $\left(\chi^{2}=38.1, \mathrm{p}=0.0015\right)$. Riders less than 35 years-old had a preference for roadsters and sports bikes, while those more than 55 years-old had rather scooters, basic or touring bikes. However, age was not associated with the outcome of LOC crashes. Thus, age could not explain the effect of motorcycle type on LOC crashes.

\section{Weekend/Weekday}

More than $40 \%$ of riders lost control at weekends; LOC risk was 2 -fold greater at weekends than on weekdays. A possible explanation is that riders more often drive in a risky way for leisure purposes at weekends, or more often ride in places that are new to them, etc.

\section{Traveling speed}

Although it is well known that speeding increases the risk of losing vehicle control, the functional relationship is not so well known. The present study provides estimates of LOC risk in relation to traveling speed for the motorcycle population. Several models were tested with different forms for speed; finally, the square of the traveling speed was used to model LOC outcome. The effect was not obvious, with a coefficient of 0.000164 . Although LOC risk increased only 1.2-fold when traveling speed increased from 50 to $60 \mathrm{~km} / \mathrm{h}$, it increased 3fold when traveling speed increased from 50 to $100 \mathrm{~km} / \mathrm{h}$, and 8-fold from 100 to $150 \mathrm{~km} / \mathrm{h}$.

The traveling speed of a motorcycle is the result of many factors such as rider behavior, characteristics of motorcycles, road conditions, etc. Hence, to test associations among those factors can help to understand the effect of traveling speed on LOC crashes. No association was found between traveling speed and blood alcohol 
concentration; however, traveling speed was found associated with age, motorcycle type, day of week, road alignment and road adhesion (respectively, $\mathrm{F}=5.66, \mathrm{p}<0.0001 ; \mathrm{F}=3.49, \mathrm{p}=0.0027 ; \mathrm{F}=5.1, \mathrm{p}=0.025 ; \mathrm{F}=11.5$, $\mathrm{p}=0.0008 ; \mathrm{F}=8.81, \mathrm{p}=0.034)$. Young motorcyclists aged between 18 and 24 were the fastest riding group. Roadster riders were more likely to speed than other riders and scooter riders had the lowest speed. Motorcyclists rode faster at weekends than on weekdays and faster on a dry road in good condition than on a road with poor adhesion. These factors were included in the multivariate final model, except age due to its lack of association to LOC.

Furthermore, the traveling speed correlates with the severity of injuries, which was considered in four categories: 1) injured, not hospitalized or hospitalized less than 24h; 2) injured, no precision about hospital stay; 3 ) injured, hospitalized more than 24h; 4) death. We found that higher speed was associated with more severe injury, with respective average speeds of $50 \mathrm{~km} / \mathrm{h}, 54 \mathrm{~km} / \mathrm{h}, 63 \mathrm{~km} / \mathrm{h}$ and $86 \mathrm{~km} / \mathrm{h}$ corresponding to these four injury categories. Although the severity of injuries was not addressed in the present paper, this correlation was expected and suggests a correct estimate of the traveling speed.

\section{Alcohol}

A very high LOC risk was found in riders with a positive blood alcohol concentration, with $O R=103$. This OR may be too high and may overestimate the risk of alcohol consumption: OR provides a good approximation of relative risk only for values close to 1 ; above a certain level of risk, the value has to be taken with caution. However, the strong effect of alcohol consumption on the likelihood of a LOC crash is undoubted, due to the well-known impairment of skills and reactions caused by alcohol. A very high proportion of drivers under influence of alcohol has been reported for single vehicle crashes in many studies: $20 \%$ of riders involved in single-vehicle crashes were under the influence of alcohol (Schneider et al. 2010); half of drivers and riders involved in fatal single-vehicle crashes had a blood alcohol concentration over $0.5 \mathrm{~g} / \mathrm{l}$ (Laumon et al. 2011).

\section{Study Limitations}

The study was subject to several limitations. The first came from the study sample. Although there were 444 cases and 470 controls, numbers were actually rather small in the control group for certain categories of studied factors, such as positive blood alcohol concentration, off-road motorcycle and unpredictable poor road adhesion, creating some uncertainty about the results, which thus need to be interpreted with caution. A weighting method was used because of the 1/20 non-fatal crashes, in order to have valid estimates, but with consequently wide variance and thus wide confidence intervals. The best study design for assessing risk factors for LOC crashes would be to sample $1 / 10^{\text {th }}$ of injury crashes, instead of all fatal crashes and $1 / 20^{\text {th }}$ of non-fatal crashes. Hence, for the same total number of crashes, subsequent analyses would not require any weighting, leading to smaller variance estimates. This might explain why not having a valid driving license was not found to be significant. Despite the richness and good quality of the data set, traveling speed was nevertheless missing in 55\% of cases due to lack of sufficient information to estimate speed. A multiple imputation technique was used, taking account of all available relevant factors associated with the missing mechanism or correlated with the traveling speed. This technique generally provides more accurate estimates than a complete-case analysis (Rubin 1987), but can generate larger confidence intervals. This might create bias in the effect of the square of the speed. Another possible bias comes from the fact that some estimated traveling speeds are grounded on the judgement of accidentology experts based on all relevant elements available in the police report, including crash 
configuration, posted speed limit or witness testimonies when informative (for example when a driver knowing his travelling speed was overtaken by the rider just before the crash).

Secondly, it should be noted that crashes without third party in non-urban areas are not always the subject of a police procedure, particularly when there is no serious outcome, and are therefore not reported systematically in national data (Amoros et al. 2006). This leads to an underestimation of not-fatal LOC motorcycle crashes and may give rise to some bias.

Thirdly, certain potential LOC risk factors, such as fatigue and sleepiness, were not available and thus not considered in the present study; drugs use was not considered either because of too many missing values and also because drug tests are usually performed by the police in certain specific cases. We had no data regarding ABS equipment and were not able to evaluate the possible efficiency of ABS, while ABS device could help avoid some LOC by keeping the wheels from locking. Tire pressure and tire wear could also play a role in LOC crashes but this information is also missing in our data.

The last limitation was the representativeness of our control group. The case-control approach is traditionally used to estimate the risk of crash involvement by comparing crash-involved versus non-crashinvolved drivers, selected at random from the population of drivers. As available data only include crash data, we chose to compare LOC motorcycle riders with a control group of crash-involved riders who did not lose control of the motorcycle, and we excluded from the latter group responsible riders. This exclusion was supposed to constitute a better representative sample of riders on the road, but this (reasonable) assumption is difficult to verify (Dufournet et al. 2016).

Despite the shortcoming of the control group, the method used allowed LOC risk to be estimated not only in relation to human error but also in relation to vehicles and road surface conditions.

\section{CONCLUSION}

This study confirms that many factors are associated with LOC crashes for motorcycles, such as riding while intoxicated, speeding or riding curves. These effects were expected, but were rarely identified and quantified in previous studies. Poor road adhesion is also shown to significantly increase the risk of losing control, particularly when deterioration of road adhesion was encountered unexpectedly (OR=28). This means that much attention has to be paid by authorities in charge of road maintenance to avoid the presence of gravel, oil, potholes on the carriageway, or otherwise to install appropriate signs systematically. Besides, the higher risk of LOC crash while riding a roadster or even more so a sports bike, which have in general a better road handling than other types of motorcycle, must be drawn to the attention of those riders as it suggests they have a tendency to over-estimate their ability or the capacity of their bikes. Other factors concerning the motorcycles such as tire condition, ABS devices, or associated with the rider behavior, such as fatigue or distraction were impossible to study from our data collection and need further investigations.

\section{ACKNOWLEDGMENTS}

This study was based on data collected as part of the Voiesur project. Particular thanks are due to the project leader, Cyril Chauvel (LAB), and the Methodology Officer in charge of determining speed, Vuthy Phan (Ceesar).

Risk factors for motorcycle loss-of-control crashes, accepted author version, 


\section{REFERENCES}

ACEM. MAIDS, in-depth investigations of accidents involving powered two wheelers. Brussels; 2009:179.

Amoros E, Martin J-L, Laumon B. Under-reporting of road crash casualties in France. Accid. Anal. Prev. 2006;38(4):627-635.

Blaizot S, Papon F, Haddak MM, Amoros E. Injury incidence rates of cyclists compared to pedestrians, car occupants and powered two-wheeler riders, using a medical registry and mobility data, Rhône County, France. Accid. Anal. Prev. 2013;58:35-45.

Bouaoun L, Haddak MM, Amoros E. Road crash fatality rates in France: A comparison of road user types, taking account of travel practices. Accid. Anal. Prev. 2015;75:217-225.

Clarke DD, Ward P, Bartle C, Truman W. The role of motorcyclist and other driver behaviour in two types of serious accident in the UK. Accid. Anal. Prev. 2007;39(5):974-981.

Creaser JI, Ward NJ, Rakauskas ME, Shankwitz C, Boer ER. Effects of alcohol impairment on motorcycle riding skills. Accid. Anal. Prev. 2009;41(5):906-913.

Dufournet M, Lanoy E, Martin J-L, Viallon V. Causal inference to formalize responsibility analyses in road safety epidemiology. eprint arXiv:1607.03775. https://arxiv.org/pdf/1607.03775v2.pdf. Published July 2016. Accessed May 24, 2017.

Elliott MA, Baughan CJ, Sexton BF. Errors and violations in relation to motorcyclists' crash risk. Accid. Anal. Prev. 2007;39(3):491-499.

Eyssartier C, Meineri S, Gueguen N. Motorcyclists' intention to exceed the speed limit on a $90 \mathrm{~km} / \mathrm{h}$ road: Effect of the type of motorcycles. Transp. Res. Part F Traffic Psychol. Behav. 2017;45:183-193.

Fredriksson R, Sui B. Powered Two-Wheeler Accidents in Germany with Severe Injury Outcome-Accident Scenarios, Injury Sources and Potential Countermeasures. In: 2016 IRCOBI Conference Proceedings. Zurich, Switzerland; 2016:12p.

Harrison WA, Christie R. Exposure survey of motorcyclists in New South Wales. Accid. Anal. Prev. 2005;37(3):441-451.

Horswill MS, Helman S. A behavioral comparison between motorcyclists and a matched group of nonmotorcycling car drivers: factors influencing accident risk. Accid. Anal. Prev. 2003;35(4):589-597.

Hurt HH, Ouellet JV, Thom DR. Motorcycle accident cause factors and identification of countermeasures Volume I: Technical Report. Traffic Saf. Cent. Univ. South. Calif. Contract No DOT HS-5-01160. 1981.

Lardelli-Claret P, Jimenez-Moleon JJ, de Dios Luna-del-Castillo J, Garcia-Martin M, Bueno-Cavanillas A, Galvez-Vargas R. Driver dependent factors and the risk of causing a collision for two wheeled motor vehicles. Inj. Prev. 2005;11(4):225-231.

Laumon B, Gadegbeku B, Martin J-L. Stupéfiants et accidents mortels (projet SAM). Paris: OFDT; 2011:166.

Lenguerrand E, Martin J-L, Moskal A, Gadegbeku B, Laumon B. Limits of the quasi-induced exposure method when compared with the standard case-control design. Accid. Anal. Prev. 2008;40(3):861-868.

Martensen H, Roynard M. MOTAC - Motorcycle accident causation - Analyse approfondie des accidents graves et mortels impliquant des motocyclistes. Bruxelles, Belgique : Institut Belge pour la Sécurité Routière Centre de Connaissance Sécurité Routière; 2013.

Michel J-E, Brenac T, Magnin J, Naude C, PERRIN C. Les pertes de contrôle en courbe. Arcueil: INRETS; 2005. 
Moskal A, Martin J-L, Laumon B. Risk factors for injury accidents among moped and motorcycle riders. Accid. Anal. Prev. 2012;49:5-11.

ONISR. La sécurité routière en France: bilan de l'accidentalité de l'année 2014. Paris: La documentation française; 2016.

Ouellet JV, Kasantikul V. The effect of blood alcohol concentration on motorcycle crash characteristics. In: Proceedings of the international motorcycle safety conference.; 2006. Available at: http://www.msfusa.org/downloads/imsc2006/Ouellet-Effect_of_BAC_on_Motorcycle_Crash_CharacteristicsPaper.pdf. Accessed May 22, 2017.

Preusser DF, Williams AF, Ulmer RG. Analysis of fatal motocycle crashes: crash typing. Accid. Anal. Prev. $1995 ; 27: 845-851$.

Rubin DB. Multiple imputation for nonresponse in surveys. New York: Wiley; 1987.

Schneider W, Savolainen P, Moore D. Effects of Horizontal Curvature on Single-Vehicle Motorcycle Crashes Along Rural Two-Lane Highways. Transp. Res. Rec. J. Transp. Res. Board. 2010;2194:91-98.

Sexton BF, Baughan CJ, Elliott MA, Maycock G, others. The accident risk of motorcyclists. 2004. Available at: http://strathprints.strath.ac.uk/20274/. Accessed February 29, 2016.

SOeS. Les deux-roues motorisés: à chaque âge, son usage et ses dangers. 2013a. Available at: http://www.statistiques.developpementdurable.gouv.fr/fileadmin/documents/Produits_editoriaux/Publications/Le_Point_Sur/2013/lps156deux-roues-motorises.pdf. Accessed February 29, 2016.

SOeS. Les deux-roues motorisés au 1er janvier 2012. 2013b. Available at: http://www.statistiques.developpementdurable.gouv.fr/fileadmin/documents/Produits_editoriaux/Publications/Chiffres_et_statistiques/2013/ch iffres-stats400-deux-roues-motorises-au-01012012-mars2013.pdf. Accessed February 29, 2016.

Stamatiadis N, Deacon JA. Quasi-induced exposure: Methodology and insight. Accid. Anal. Prev. 1997;29(1):37-52.

Teoh ER, Campbell M. Role of motorcycle type in fatal motorcycle crashes. J. Safety Res. 2010;41(6):507-512.

Van Buuren S. multiple imputation of discrete and continuous data by fully conditional specification. Stat. Methods Med. Res. 2007;16(219-242).

Van Elslande P, Elvik R. Powered two-wheelers within the traffic system. Accid. Anal. Prev. 2012;49:1-4.

Van Elslande P, Perrin C, Hermitte T. Rapport de synthèse final du projet "2RM"(R 7.2). France; 2008.

VOIESUR. ANR. 2012. Available at: http://www.agence-nationale-recherche.fr/en/anr-fundedproject/?solr=run\&tx_lwmsuivibilan_pi2\%5BCODE\%5D=ANR-11-VPTT-0007. Accessed July 20, 2017. 


\section{Appendix}

\section{Text A1: Types of motorcycles}

\section{Scooter:}

Scooters are characterized by small wheels and a comfortable driving position that allows riders to place their feet on a platform. They usually have small engines and are used in the city for a short distance trip.

Basic:

Basic motorcycles are characterized by their simple design conception with few styling frills. They have an upright riding position which is similar to that of a roadster and a cruiser. They are simple to ride and to maintain, more adaptable for daily trips and cheaper than other types.

\section{Roadster:}

Roadsters are characterized by the absence of fairing and have a design between basic and sport bike. They have a simple design with certain esthetic and showy frills, and with a sportive engine. The majority of roadsters have an engine displacement between 600 and $1200 \mathrm{~cm}^{3}$.

\section{Cruiser:}

Cruisers are characterized by no fairing coverage and a specific riding position with the feet forward to the front and high and wide-set handlebars.

Tourer/grand tourer:

Touring or grand touring motorcycles are designed for comfortable, long distance travels. They are equipped with high-displacement engines, luggage and wind protection.

Sports bike:

Sports bikes are derived from the road-racing motorcycles. They are equipped with high-displacement engines and full fairing. They are lighter and smaller than touring motorcycles, with a forward-leaning riding position. So they are capable of high speed, acceleration, cornering.

\section{Dual-purpose:}

Dual-purpose motorcycles can be used both off-road and on-road. They are similar to off-road motorcycles, with some added equipments designed to adapt to the road.

Off-road:

As the name suggests, they are designed for off-road use. They are characterized by no fairing, long travel suspension and knobby tires designed to provide more grip on surfaces not paved. They are light weight and typically equipped with small-displacement engines. 
Table A1: Distribution of cases and controls according to potential risk factors for motorcycle loss-of-control crash involvement, crude OR and 95\% CI (observed frequency and weighted column percentage)

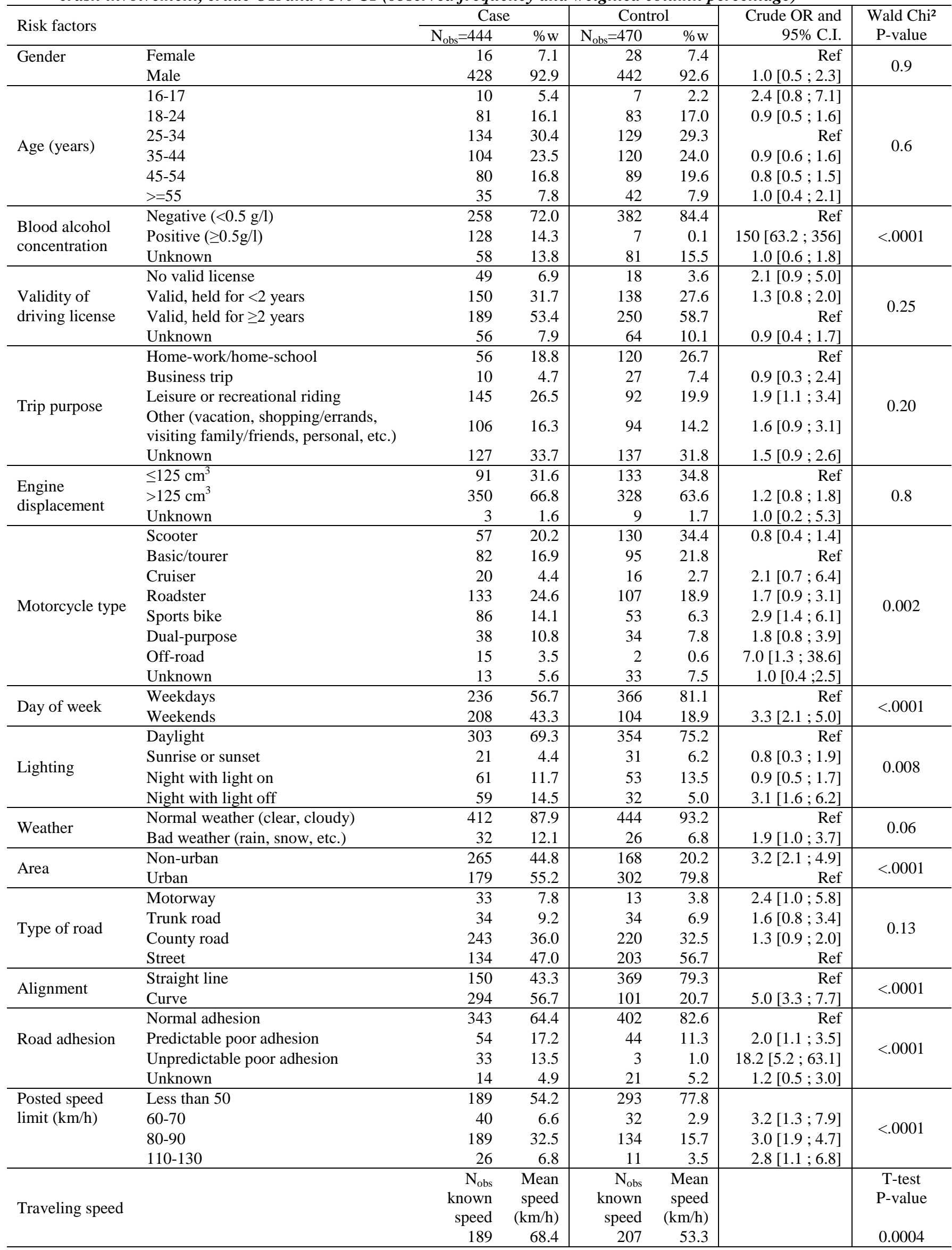

$* N_{\text {obs }}:$ number of observations; $N_{\text {obs }}$ known speed: number of observations with non-missing speed

Risk factors for motorcycle loss-of-control crashes, accepted author version, http://dx.doi.org/10.1080/15389588.2017.1410145 